\title{
A New Three-Phase Boost-Type Voltage Regulator With Unity Input Power Factor
}

\author{
T. S. Radwan*, A. E. Lashine*, and M. A. Rahman** \\ Electrical Engineering Department, \\ Faculty of Engineering, Menoufiya University, \\ Shebin El-Kom, Egypt* \\ Memorial University of Newfoundland, Faculty of Engineering \& Applied Science, \\ St. John`s, A1B 3X5, NF, Canada**
}

\begin{abstract}
This paper presents a new configuration for high performance three-phase voltage boost regulator. For this new configuration, a control methodology is proposed to provide regulated ac output voltage. The new boost regulator has nearly unity input power factor for a change in the load voltage from $100 \%$ to more than $200 \%$ of the supply voltage. At these conditions, a nearly ripple free output voltage is achieved. The four-quadrant nature of the proposed regulator enables it to accept reactive loads. Theoretical analysis and practical controller implementation are presented and the efficacy of the proposed regulator has been confirmed.
\end{abstract}

Key words: voltage regulator; power factor correction.

\section{Introduction}

$\mathrm{AC}$ regulators are widely used in applications requiring power control, voltage regulation and reactive power compensation. These are also used in special motor drive systems such as self-starting induction motors and speed controllers for fans and pumps. Most of the existing systems are conventional line commutated ac controllers with thyristor technology. These conventional controllers cause discontinuity and significant harmonics in load and supply currents. Also, these systems are suitable only for buck mode applications. A thyristor-controlled transformer booster has been suggested and examined [1], but such devices are of limited range and introduce distortion in the voltage waveform. Saturable reactor voltage regulator with improved current waveform was obtained [2], but distortion was noticeable at low levels of output voltage. Different topologies and control techniques were proposed [3] to realize unity power factor at the ac source side, but large number of switches and sophisticated control techniques were required for the ac-dc-ac conversion system

Line commutated ac regulators can be replaced by PWM ac regulators which have better overall performance. PWM ac regulators are designed with standard gate commutated devices like BJT, GTO, MOSFET, IGBT, etc. The advantages to be gained include sinusoidal input-output current/voltage waveforms, better input power factor and substantially smaller input/output filters. The PWM controlled ac/ac voltage regulators has been examined in $[4,5]$. Although high input power factor has been achieved, these types of regulators were used in the buck mode only. Another technique has been used for ac/ac regulation based on electronic transformer [6]. Several possible topologies employing static converters connected on the primary and secondary sides in combination with magnetic circuits were explored to realize a high frequency ac link. Although electronic transformer gave higher efficiency and better voltage regulation, large number of switches and sophisticated control techniques were required.

In this paper, a new topology for high performance three-phase boost regulator is proposed. The principle of operation and control of the regulator are presented. The new boost regulator has nearly unity input power factor. A $750 \mathrm{VA}$ laboratory prototype of the boost regulator has been built and tested. Simulation and experimental results are reported and discussed.

\section{Proposed Topology}

\subsection{The power circuit}

Fig.1 illustrates the bi-directional three-phase boost-type ac voltage regulator proposed in this paper. In this approach, only four ac switches, $\mathrm{S}_{\mathrm{a} a}, \mathrm{~S}_{\mathrm{ac}}, \mathrm{S}_{\mathrm{bb}}, \mathrm{S}_{\mathrm{bc}}$, are used and arranged as shown in the figure. The ac switches and the boost inductors, $\mathrm{L}_{\mathrm{Ba}}, \mathrm{L}_{\mathrm{Bb}}, \mathrm{L}_{\mathrm{Bc}}$, are located between the ac source and the load. Moreover, three star-connected ac capacitors are located across the load terminals. The proposed approach has its inherent capability in the applications where bi-directional power flow is important, such as in a motor drive.

Since only four ac switches are to be controlled, it needs only four driving circuits for the corresponding ac switches. Moreover, the proposed arrangement of the ac switches prevents the switches from conducting simultaneously as in bridge leg configuration. So, no deadtime has to be considered in this topology. This will simplify the controller design greatly. The ac switch can be constituted by one or two power transistors [7]. It can conduct bidirectional currents when turned on and block ac voltages when turned off. Fig. 2 shows two schematics to configure an ac switch. 


\subsection{The control strategy}

In the proposed regulator, only two independent hyster sis current controllers are used. Fig. 3 shows the block diagram of the control strategy. The voltage reference signal, $\mathrm{V}_{\text {ref, }}$ is set according to the required load voltage. This signal can be treated as a dc value which is proportional to the load phase voltage. Using a peak value detector, the phase voltage $V_{a}$ is converted to a corresponding dc value, $V_{a d c}$. This value is compared with the reference voltage signal, $\mathrm{V}_{\mathrm{ref}}$, and the error signal is passed through a proportional controller $\left(k_{p v}\right)$

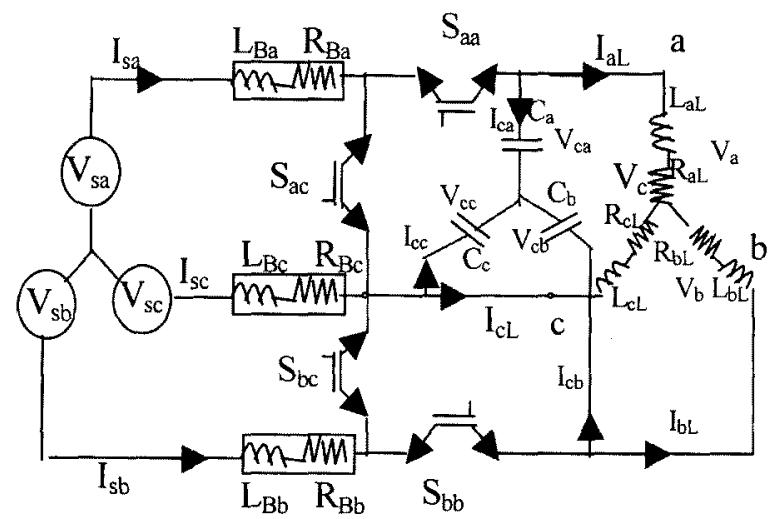

Fig. 1 The proposed three-phase boost-type voltage regulator.
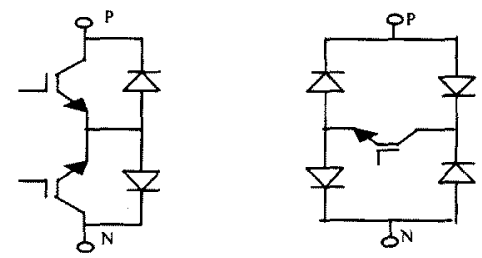

Fig. 2 Configuration of ac switches

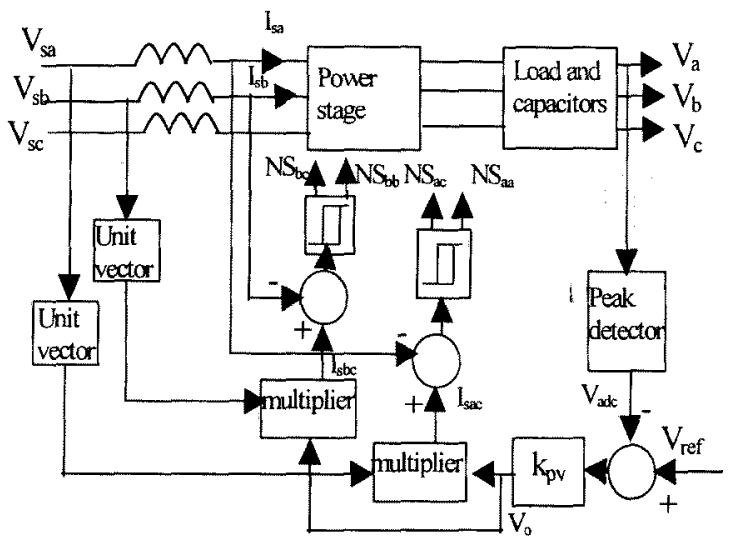

Fig. 3 Block diagram of the proposed control strategy.
The output of the controller, $V_{0}$ is then multiplied by the unit vector of the supply phase voltages $V_{s a}$ and/or $V_{s b}$ to produce the command currents $I_{\mathrm{sac}}$ and $\mathrm{I}_{\mathrm{sbc}}$, respectively. The supply currents $I_{\mathrm{sa}}$ and $\mathrm{I}_{\mathrm{sb}}$ are compared with their corresponding commands, $\mathrm{I}_{\mathrm{sac}}$ and $\mathrm{I}_{\mathrm{sbc}}$, and the errors are processed through two independent hysteresis controllers. The outputs of the hysteresis controllers are in the form of binary signals, $\mathrm{NS}_{\mathrm{aa}}, \mathrm{NS}_{\mathrm{ac}}, \mathrm{NS}_{\mathrm{bb}}$ and $\mathrm{NS}_{\mathrm{bc}}$. If the input current is greater than the current command, the digital signal is ' $0^{\prime}$. Otherwise it is ' 1 '. Note that the logic $\mathrm{NS}_{\mathrm{ac}}$ is a complementary of logic $\mathrm{NS}_{\mathrm{aa}}$ and similarly, the logic $\mathrm{NS}_{\mathrm{bc}}$ is a complementary of logic $\mathrm{NS}_{\mathrm{bb}}$ as given in Table $\mathrm{I}$. Those logic signals will be used to fire the four ac switches. If the supply current is controlled to follow the current command, it follows the supply voltage in its waveform and follows the reference voltage in its magnitude. This is easily achieved, since the reference current is generated from and synchronized with the supply voltage. This control strategy ensures that the input power factor is almost kept at unity over wide range of the load power factor by adjusting the capacitors.

\subsection{Modes of operation}

Since the logics $\mathrm{NS}_{\mathrm{ac}}$ and $\mathrm{NS}_{\mathrm{bc}}$ are complementary of logics $\mathrm{NS}_{\mathrm{aa}}$ and $\mathrm{NS}_{\mathrm{bb}}$, respectively, the truth table can be established for the different modes of operation of the boost regulator as given in Table I. It seems from the truth table that four modes of operation are possible.

Mode 1: $S_{a a}, S_{b b} O N$ and $S_{a c}, S_{b c} O F F$ : In this mode the supply voltage is connected directly to the load. Supply currents flow to the load through the boost inductors. At the same time, the $\mathrm{Y}$-connected capacitors are charged. This mode continues until the supply currents $I_{\mathrm{sa}}$ and/or $I_{\mathrm{sb}}$ decrease less than or equal to $\left(I_{s a, b, c}-H\right)$, where $H$ is the hysteresis band.

Mode 2: $S_{a c}, S_{b c} O N$ and $S_{a a}, S_{b b} O F F$ : In this mode, the control circuit allows the supply currents to increase. At the same time, the stored energy in capacitors discharges into the load. When $I_{s a}$ and/or $I_{s b}$ increase to be more than or equal to $\left(\mathrm{I}_{\mathrm{s} a, b, c}+\mathrm{H}\right), \mathrm{S}_{\mathrm{ac}}$ and/or $\mathrm{S}_{\mathrm{bc}}$ are turned off.

Mode 3: $S_{a a}, S_{b c}$ ON and $S_{b b}, S_{a c}$ OFF: During this mode, the energy stored in the boost inductors is transferred to the capacitors giving rise to the capacitors voltage to increase. At the same time, $l_{s b}$ flows through $L_{B b}$ and $S_{b c}$ until its boosting period.

Mode 4: $S_{b h}, S_{a c} O N$ and $S_{a a}, S_{b c} O F F$ : This mode is similar to Mode 3, except that phases ' $a$ ' and ' $b$ ' are interchanged.

Table I. Truth table for the modes of operation.

\begin{tabular}{|c|c|c|c|c|}
\hline $\mathrm{NS}_{\mathrm{bc}}=\overline{\mathrm{NS}_{\mathrm{bb}}}$ & $\mathrm{NS}_{\mathrm{bb}}$ & $\mathrm{NS}_{\mathrm{ac}}=\overline{\mathrm{NS}}_{\mathrm{aa}}$ & $\mathrm{NS}_{\mathrm{aa}}$ & Mode \\
\hline 0 & 1 & 0 & 1 & 1 \\
\hline 1 & 0 & 1 & 0 & 2 \\
\hline 1 & 0 & 0 & 1 & 3 \\
\hline 0 & 1 & 1 & 0 & 4 \\
\hline
\end{tabular}




\section{Modeling and Analysis}

For all modes of operations the following general equations can be deduced;

Load equations:

$\mathrm{V}_{c a}-\mathrm{V}_{\mathrm{cb}}=\mathrm{I}_{\mathrm{aL}} \mathrm{R}_{\mathrm{aL}}+\mathrm{L}_{\mathrm{aL}} \frac{\mathrm{dI}_{\mathrm{aL}}}{\mathrm{dt}}-\mathrm{I}_{\mathrm{bL}} \mathrm{R}_{\mathrm{bL}}-\mathrm{L}_{\mathrm{bL}} \frac{\mathrm{dI}_{\mathrm{bL}}}{\mathrm{dt}}$

$v_{c b}-v_{c c}=I_{b L} R_{b L}+L_{b L} \frac{d l_{b L}}{d t}-I_{c L} R_{c L}-L_{c L} \frac{d_{c L}}{d t}$

$\mathrm{I}_{\mathrm{cL}}=-\mathrm{I}_{\mathrm{aL}}-\mathrm{I}_{\mathrm{bL}}$

Capacitances equations:

$\mathrm{V}_{\mathrm{ca}}=\frac{1}{\mathrm{Ca}} \int \mathrm{I}_{\mathrm{ca}} \mathrm{dt}$

$\mathrm{V}_{\mathrm{cb}}=\frac{1}{\mathrm{Cb}} \int \mathrm{l}_{\mathrm{cb}} \mathrm{dt}$

$\mathrm{v}_{\mathrm{cc}}=\frac{1}{\mathrm{Cc}} \int \mathrm{I}_{\mathrm{cc}} \mathrm{dt}$

Currents equations

$\mathrm{I}_{\mathrm{cb}}=-\left(\mathrm{I}_{\mathrm{ca}}+\mathrm{I}_{\mathrm{cc}}\right)$

$I_{s b}=-\left(I_{s a}+I_{s c}\right)$

When switch $S_{\text {aa }}$ is on the following equations can be derived:

$$
\begin{aligned}
V_{s a}-V_{s c}=I_{s a} R_{B a}+L_{B a} \frac{d_{s a}}{d t}-I_{s c} R_{B c} & -L_{B c} \frac{d l_{s c}}{d t} \\
& +V_{c a}-V_{c c}
\end{aligned}
$$

$\mathrm{I}_{\mathrm{ca}}=\mathrm{I}_{\mathrm{sa}}-\mathrm{I}_{\mathrm{aL}}$

When switch $S_{b b}$ is on the following equations can be derived:

$$
\begin{aligned}
V_{s b}-V_{s c}=I_{s b} R_{B b}+L_{B b} \frac{d I_{s b}}{d t}-I_{s c} R_{B c} & -L_{B c} \frac{d I_{s c}}{d t} \\
& +V_{c b}-V_{c c}
\end{aligned}
$$

$I_{c c}=I_{s c}-I_{c L}$

When switch $S_{a c}$ is on the following equations can be derived:

$V_{s a}-V_{s c}=I_{s a} R_{B a}+L_{B a} \frac{d l_{s a}}{d t}-I_{s c} R_{B c}-L_{B c} \frac{d_{s c}}{d t}$

$\mathrm{I}_{\mathrm{ca}}=-\mathrm{I}_{\mathrm{aL}}$

When switch $S_{b c}$ is on the following equations can be derived:

$V_{s b}-V_{s c}=I_{s b} R_{B b}+L_{B b} \frac{d I_{s b}}{d t}-I_{s c} R_{B c}-L_{B c} \frac{d l_{s c}}{d t}$

$I_{c b}=-I_{b L}$

Equations(1-12) cover Mode 1, while Eqs. (1-8) and Eqs. (13-16) cover Mode 2. Also, Eqs (1-10) and Eqs.(15-16) cover Mode 3, while Eqs.(1-8) and Eqs (11-14) cover Mode 4.

The circuit parameters, boost inductors and output capacitors, can be determined according to the range of the switching frequency and acceptable percentage of the output ripple. Consider Eqs. (9-12) the rate of change of $I_{s, b, c}$ is determined by the values of $L_{B} a, b, c$ during Mode 1 and by the values of $L_{B} a, b, c$ and $C_{a, b, c}$ during Mode 2 . Accordingly, the switching frequency is determined by these values depending on the hysteresis band, $\mathrm{H}$. The value of the hysteresis band, $\mathrm{H}$, is set as $10 \%$ of the command current to give acceptable switching frequency and consequently low harmonics.

Assuming balanced three-phase supply and $I_{5 n}$ is the rms value of the $n$-th harmonic component of the supply current, the input distortion factor $\mathrm{DF}_{\mathrm{s}}$ is defined as:

$D F_{S}=\sqrt{\left(\sum_{n=2}^{\infty} \mathrm{I}_{\mathrm{Sn}}^{2}\right) / \mathrm{I}_{\mathrm{sl}}^{2}}$

Where $I_{s 1}$ is the rms value of the fundamental component of the supply current. The input power factor is given by:

$\mathrm{PF}_{\mathrm{S}}=\cos \phi_{1} / \sqrt{1+\left(\mathrm{DF}_{\mathrm{S}}\right)^{2}}$

where $\phi_{1}$ is the angle between the fundamental component of the supply current, $I_{s 1}$, and the phase supply voltage $\mathrm{V}_{\mathrm{sa}}$.

The load distortion factor $\mathrm{DF}_{\mathrm{L}}$ is defined as:

$D F_{L}=\sqrt{\left(\sum_{n=2}^{\infty} X_{n}^{2}\right) / X_{1}^{2}}$

where $X$ may represents current or voltage and $X_{n}$ is the rms value of $n$-th harmonic component of the load voltage or the load current. On the other hand, $X_{1}$ is the rms value of the fundamental component of the load voltage or the load current.

Equations (1-16) are used to simulate the boost regulator by the help of Matlab/Simulink Toolbox [8]. The Simulink /Toolbox uses the metaphors of a block diagram to represent the system.

\section{Real Time Implementation}

The control scheme of Fig. 3 is implemented in real time using a 32-bit digital signal processor (DSP) (TMS320C31), as shown in Fig. 4. The ac switches are constructed using insulated gate bipolar transistors (IGBTs) with ultra-fast recovery diodes as a bridge. The voltage isolators sense the unit vectors of the supply voltages. These sensed signals are used for synchronization of the generated reference currents. The supply currents, $I_{s a}$ and $I_{s b}$, are measured by using Hall-effect devices. The voltage and current signals are then fed to the DSP through 12-bit A/D converters. The output from the DSP (digital $\mathrm{I} / \mathrm{O}$ ) is in the form of logic pulses, $\mathrm{NS}_{\mathrm{aa}}, \mathrm{NS}_{\mathrm{ac}}, \mathrm{NS}_{\mathrm{bb}}$ and $\mathrm{NS}_{\mathrm{bc}}$. These logic pulses are then fed to the ac switches through isolation and driving stage. The overall execution time of the control scheme is $45 \mu \mathrm{sec}$ at sampling frequency of $20 \mathrm{kHz}$.

\section{Simulation and Experimental Results}

An experimental three-phase boost-type voltage regulator with the proposed control strategy has been built and 
tested. The laboratory model has been constrained to power ratings of 750VA. However, the results reported here are applicable to other types of load and thus have universal applications by resorting to the usual scaling law.

Simulation and experiment are carried out to determine the characteristics of the proposed boost regulator. The circuit parameters of the prototype are listed in the Appendix. The supply voltage is kept constant at $35 \mathrm{~V} /$ phase and the reference voltage is controlled to allow boosting of the output voltage.

Fig. 5 shows the simulation results of the three-phase regulator for the boosting of $150 \%$ of the input voltage. Fig. 5(a) shows the supply phase voltage $\left(\mathrm{V}_{\mathrm{sa}}\right)$ and the supply phase current $\left(\mathrm{I}_{\mathrm{sa}}\right)$. It is clear from Fig.5 (a) that the supply current follows the supply voltage in its wave shape with almost a unity displacement power factor. The use of two independent hysteresis current controllers ensures balanced three-phase currents, as shown in Fig.5 (b). Also, the proposed control strategy ensures symmetrical load voltages as shown in Fig. 5(c). Moreover, it is evident from Fig. $5(\mathrm{c})$ that the load voltage is almost $150 \%$ of the input voltage. The phase load voltage and current are shown in Fig. 5(d). The experimental results in Fig. 6 confirm, very closely, the corresponding simulated results of Fig. 5 .

Similar results were obtained by setting the reference voltage for the boosting of $200 \%$. Fig. 7 shows the simulation results of the proposed regulator in this case. In Fig. $7(a)$, the supply phase current $\left(I_{\mathrm{sa}}\right)$ is nearly in phase with the supply phase voltage $\left(\mathrm{V}_{\mathrm{sa}}\right)$. Also, the controller has the ability not only to force balanced supply currents, but also to force balanced load voltages, as shown in Figs. 7(b) and (c). The per- phase load voltage and current are shown in Fig. $7(\mathrm{~d})$. The experimental results of Fig. 8 also confirm the simulated results of Fig. 7. Fig. 9 shows the power factor, distortion factor of the supply current and distortion factor of the load current over a wide range of load voltage. The results show the effectiveness and efficacy of the proposed controller for boosting operation.

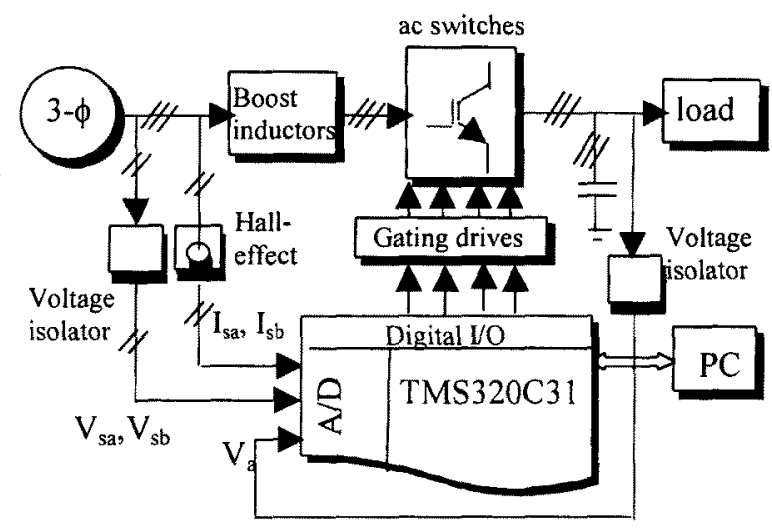

Fig. 4 Hardware implementation

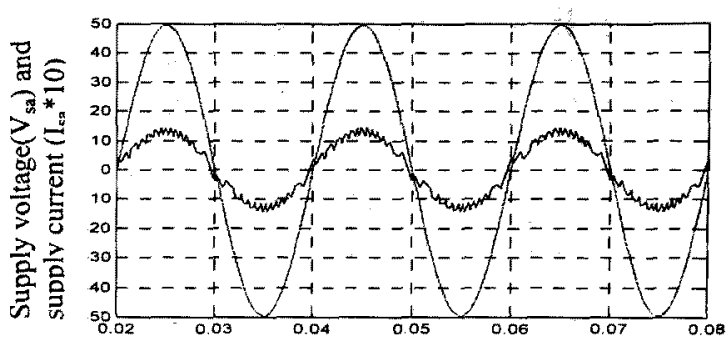

Time (sec)

(a)
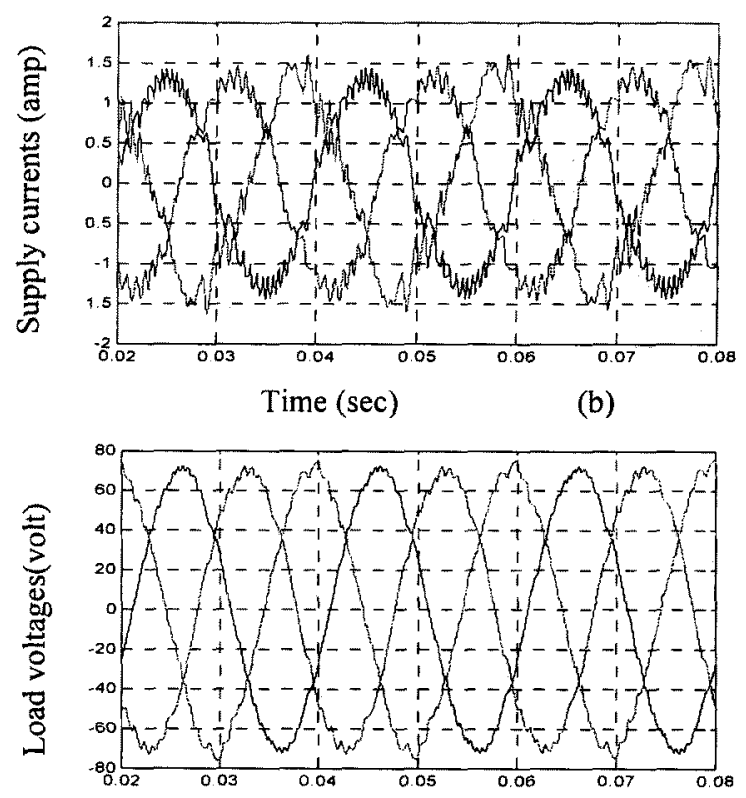

Time (sec)

(c)

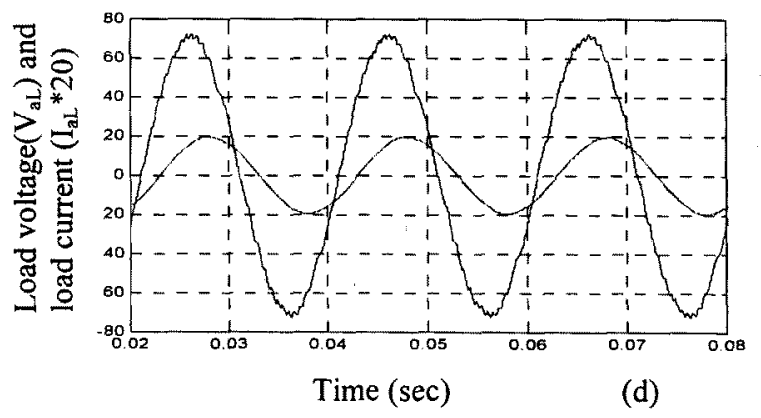

Fig. 5 Simulation of $150 \%$ boosting mode; (a) supply voltage and current; (b) supply currents; (c) load voltages; and (d) load voltage and current.

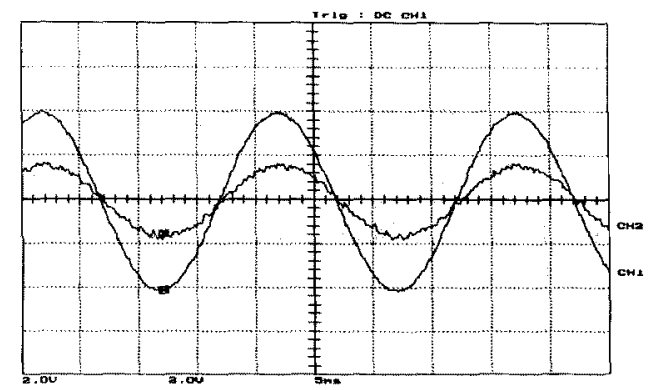

(a) 


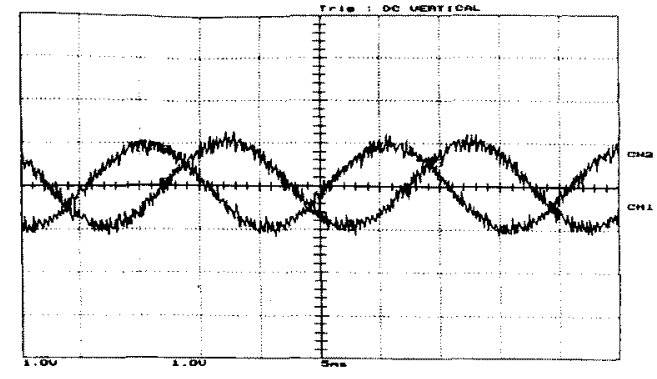

(b)

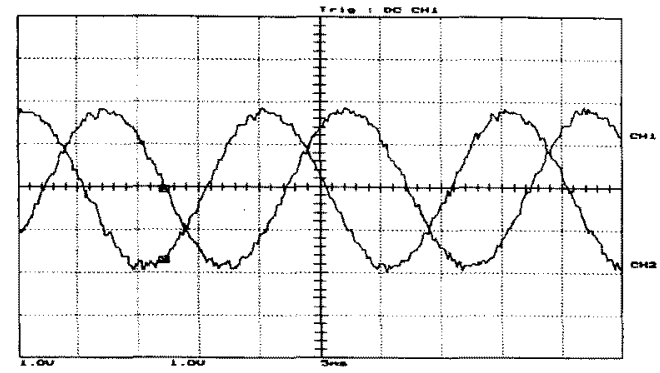

(c)

Fig.6 Experimental results of $150 \%$ boosting mode; (a) supply voltage and current, $V_{\mathrm{sa}}=25 \mathrm{~V} / \mathrm{div}, 1_{\mathrm{sa}}=2 \mathrm{~A} / \mathrm{div}$; (b) supply currents, $1.5 \mathrm{~A} / \mathrm{div}$; (c) load voltages, $40 \mathrm{~V} / \mathrm{div}$.
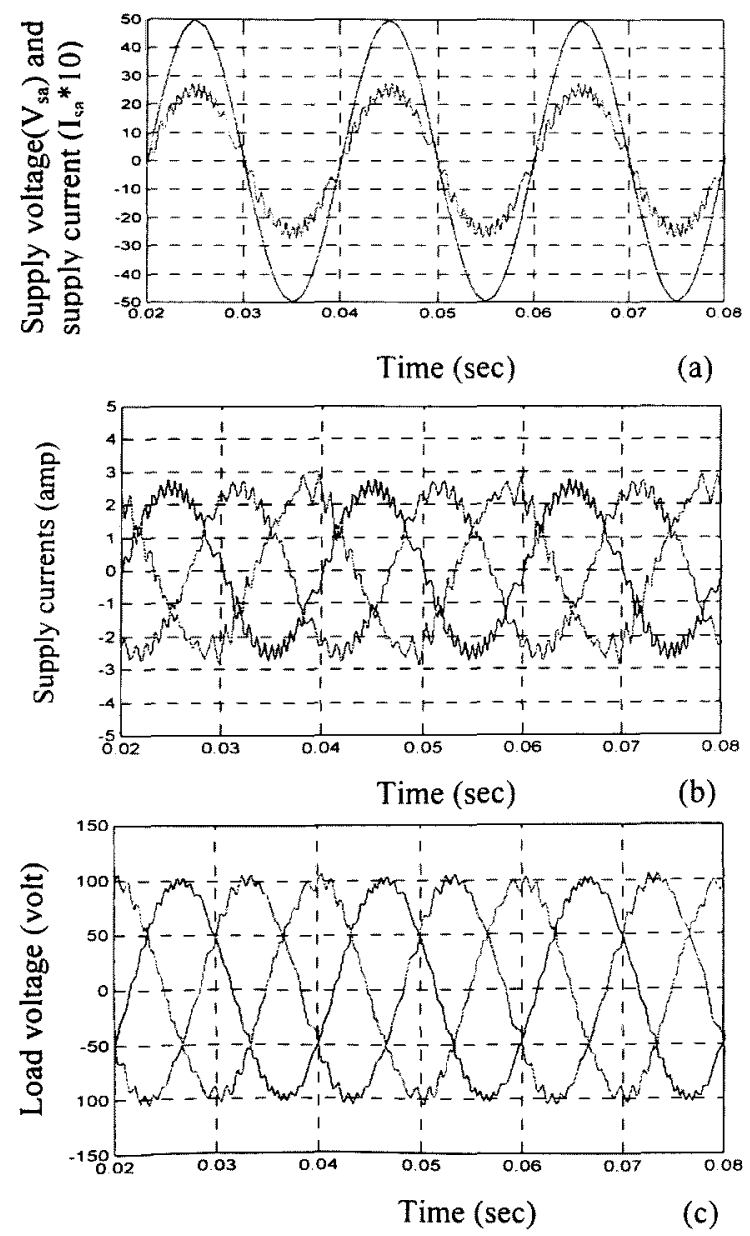

電学諭D, 120 巻 12 号, 平成 12 年

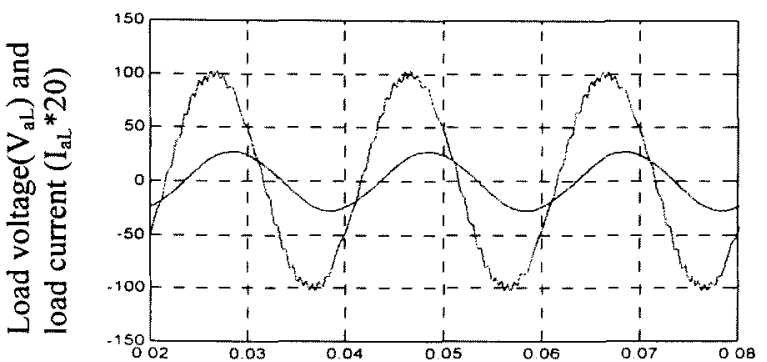

Time (sec)

(d)

Fig. 7 Simulation of $200 \%$ boosting mode; (a) supply voltage and current; (b) supply currents; (c) load voltages; and (d) load voltage and current.

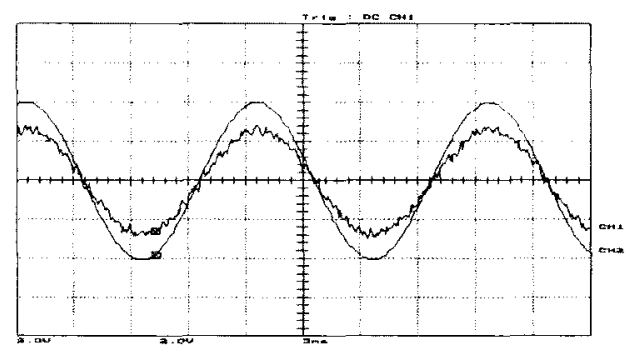

(a)

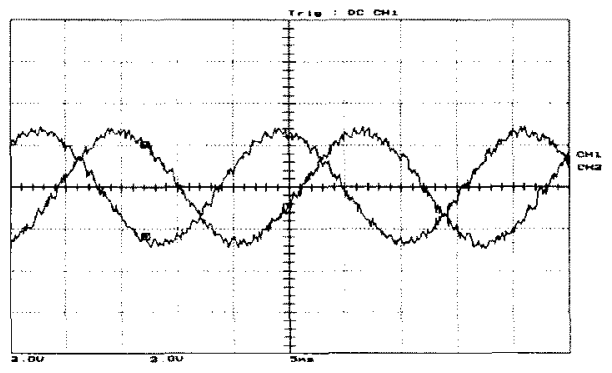

(b)

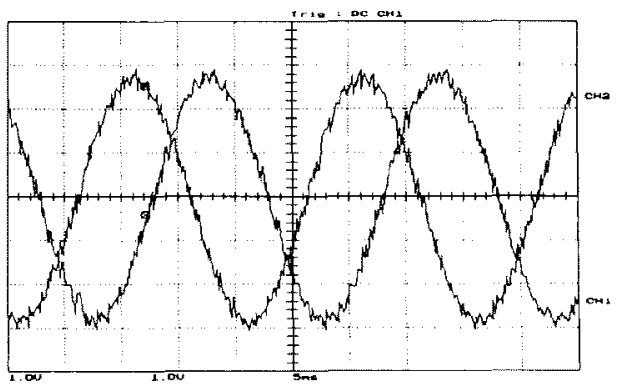

(c)

Fig.8 Experimental results of $200 \%$ boosting mode; (a) supply voltage and current, $\mathrm{V}_{\mathrm{sa}}=25 \mathrm{~V} / \mathrm{div}, \mathrm{I}_{\mathrm{sa}}=2.2 \mathrm{~A} / \mathrm{div}$; (b) supply currents, $2.2 \mathrm{~A} / \mathrm{div}$; (c) load voltages, $35 \mathrm{~V} / \mathrm{div}$. 


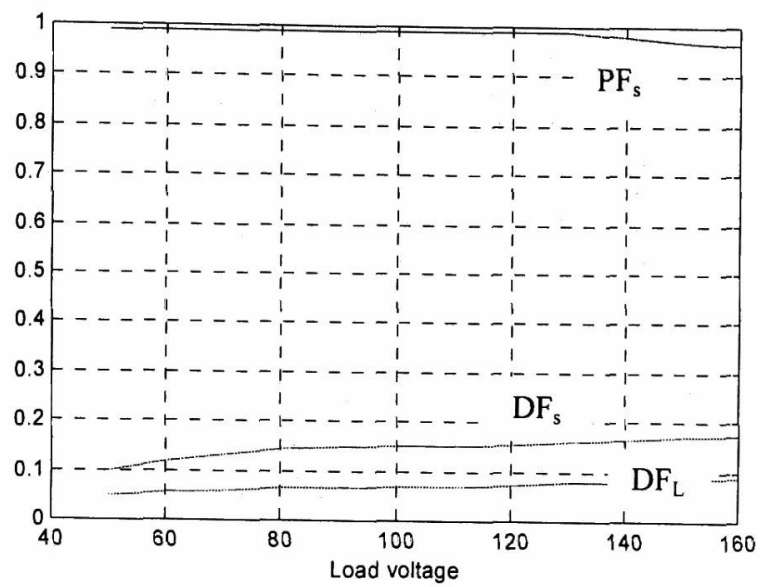

Fig. 9 Simulated results of supply power factor, supply current distortion factor and load current distortion factor versus load voltage.

\section{Conclusions}

A new three-phase boost-type voltage regulator with nearly unity input power factor has been proposed. A control scheme using two independent hysteresis current controllers has been also proposed. The operation and modeling of the boost regulator have been described and analyzed. Since the regulator employed only four ac switches, the presented approach makes the operational principles clear and gives the possibility of simple control design and implementation. Only two of the four-ac switches are controlled at a time. This reduces the overall switching power losses. The regulator is effectively an electronic step-up coreless transformer. It has the ability to step up the voltage to more than $200 \%$. An experimental regulator has been built and tested to explore the advantages and the practical limitations of this new three-phase boost-type voltage regulator.

(Manuscript received Jan., 21, 2000, revised Jun 21,2000)

\section{References}

[1] J. Arrillaga and R. M. Duke, "A static alternative to the transformer on-load tap changer" , IEEE Transactions on Power Apparatus and System, PAS-099, no.1, pp.86-91, 1980.

[2] A. E. Lashine, “ A thyristorized saturable reactor with self excitation", Electric Machines and Power Systems, USA, vol. 24, no.4, pp.437-449, 1996.

[3] D. M. Divan, "Inverter topologies and control techniques for sinusoidal output power supplies", IEEE/APEC Conference Record, vol. 1, pp.81-87, 1991

[4] K. M. Rahman, M. A. Choudhary and M.A. Rahman, "Hysteresis current controlled PWM buck converter for ac/ac voltage control", Proceedings of the International Power Engineering Conference, vol. II, Singapore, 22-24, pp.703-706, May 1997.
[5] R. Strzelecki and Z. Fedyczak, "Properties and structures of three-phase PWM ac power controllers", IEEE-PESC'96, pp.740-746, 1996

[6] M. Kang, P. N. Enjeti and I. J Pitel, " Analysis and design of electronic transformers for electric power distribution system", IEEE-IAS Annual Meeting, Neworleans, Louisiana, pp. 1689-1694, October 1997.

[7] T. S. Radwan, A. E. Lashine and M. A. Rahman, "A Novel ac/ac buck-boost voltage regulator with unity input power factor" International Journal of Electronics, UK, vol.87, no.2, pp.199-210, Feb. 2000.

[8] SIMULINK with MATLAB, The MathWorks, Inc., Natick, MA., 1993.

\section{Appendix I}

Data and circuit parameters

$\mathrm{V}_{\mathrm{sa}}=\mathrm{V}_{\mathrm{sb}}=\mathrm{V}_{\mathrm{sc}}=35 \mathrm{~V}, \quad \mathrm{~L}_{\mathrm{Ba}}=\mathrm{L}_{\mathrm{Bb}}=\mathrm{L}_{\mathrm{Bc}}=30 \mathrm{mH}$

$\mathrm{R}_{\mathrm{Ba}}=\mathrm{R}_{\mathrm{Bb}}=\mathrm{R}_{\mathrm{Bc}}=1.4 \Omega, \quad \mathrm{C}_{\mathrm{a}}=\mathrm{C}_{\mathrm{b}}=\mathrm{C}_{\mathrm{c}}=15 \mu \mathrm{F}$

Load side; three phase balanced R-L with $R_{L}=60 \Omega$ and $\mathrm{L}_{\mathrm{L}}=130 \mathrm{mH}$. Proportional gain, $\mathrm{Kpv}=5$.

Tawfik S. Radwan He was born in Gharbiya, Egypt in 1963.

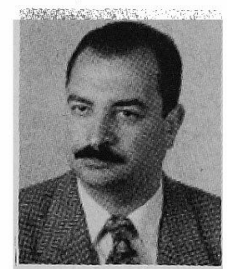
$\mathrm{He}$ received the B.Sc., M.Sc. and Ph. D. degrees all in electrical engineering from Menoufiya University, Egypt, in 1986, 1992 and 1996, respectively. He joined as an Instructor in the same University in 1986 . He became an Assistant Lecturer in 1992, Assistant Professor in 1996. From January 1994 to January 1996 he was a $\mathrm{Ph}$. D. student at Memorial University of Newfoundland (MUN), Canada under academic channel program. He was a Visiting Research Associate at Memorial University of Newfoundland during the summers of 1997, 1998 and 1999. His fields of interests are ac motor drives and power electronics.

Azza E. Lashine She was born in Tanta, Egypt, in 1958. She

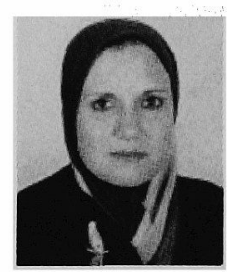
received the B.Sc., M. Sc. and Ph. D. degrees in electrical engineering from Menoufiya University, Egypt, in 1980, 1985 and 1989, respec tively. She was appointed as a Demonstrator at Menoufiya University in December 1981 and became an Assistant Lecturer in January 1985. She was Associate Professor in 1994. She is current a Professor in the Department of Electrical Engineering, Faculty of Engineering. Her current interests include power electronics and its applications. 
M. Azizur Rahman He was born in Santahar, Bangladesh in

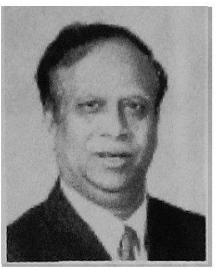

1941. He received the B. Sc. degree in electrical engineering from Bangladesh University of Engineering and Technology (BUET), Dhaka, the M. A.Sc. degree from the University of Toronto, Ont., Canada, and the $\mathrm{Ph} . \mathrm{D}$. degree from Carleton University, Ottawa, Ont., Canada, in 1962, 1965 and 1968, respectively. In 1962, he joined the Department of Electrical Engineering BUET, as a Lecturer. He became An Assistant Professor in 1969, Associate Professor in 1972 and Professor in 1975. In 1976, he joined the Memorial University of Newfoundland, Canada, where in now a Professor. He was a University research Professor during the term 1993-1998. He has 37 years of teaching including 10 years of full-time of concurrent industrial, utility and consulting experience. He has published more than 400 papers including eight patents, and two books. His current research interests are in machines, power system, digital protection and power electronics. He has been stowed upon with numerous awards including IEEE Notable Service Award for contributions in IEEE and Engineering Professions in 1987, IEEE Industry Application Society's Outstanding Achievement Award in 1992, the Association of Professional Engineers merit Award in 1994, and the IEEE Canada Outstanding Engineering Educator's Medal in 1996. He is a registered Professional Engineer in the Provinces of Newfoundland and Ontario, Canada, a Fellow of the Institution of Electrical Engineers, U. K., a fellow of the Institution of Engineers, Canada, a Fellow of the Institution of Electrical and Electronics Engineers, USA and a Life Fellow of the Institution of Engineers, Bangladesh. 